\title{
Burden sharing in deficit countries: a questionnaire-experimental investigation
}

\author{
Wulf Gaertner ${ }^{1,2} \cdot$ Lars Schwettmann $^{3,4}$
}

Received: 11 July 2016 / Accepted: 8 November 2016 / Published online: 23 November 2016 (C) The Author(s) 2016. This article is published with open access at Springerlink.com

\begin{abstract}
This paper studies the problem of burden sharing in countries that were forced to introduce severe budget cuts after the collapse of Lehman Brothers in 2008 which had unleashed a financial crisis in many industrialised countries of the Western world. We do not ask how the burden was actually split in each country examined but how the burden should have been shared among different income groups of society. In order to answer this question, a questionnaire-experimental investigation was run among students from Cyprus, Greece, Ireland, Italy, Portugal, and Spain. Our study offered the students seven different schemes of taxation amongst which we had specified a proportional rule and two progressive schemes of differing severity. A key result within our investigation is the finding that a large majority of students in all countries involved rarely opted for a proportional rule of burden sharing but picked one of the two progressive schemes instead. However, there were differences between countries with respect to the frequencies of these three rules, whereby Greece and Ireland were polar cases. The other rules received only minor support.
\end{abstract}

Keywords Burden sharing · Proportional rule · Progressive schemes · Questionnaire studies

$\bowtie \quad$ Lars Schwettmann

lars.schwettmann@helmholtz-muenchen.de

1 Department of Economics, University of Osnabrück, Rolandstraße 8, D-49069 Osnabrück, Germany

2 CPNSS, London School of Economics, London WC2A 2AE, UK

3 Institute for Health Economics and Health Care Management, Helmholtz Zentrum München GmbH, Postfach 1129, D-85758 Neuherberg, Germany

4 Department of Economics, Martin Luther University Halle-Wittenberg, Universitätsring 3, D-06108 Halle, Saale, Germany 
JEL Classification D31 · D63 · D71 · H24

\section{Introduction}

During the last decades public debt continually increased in almost all member states of the European Union with only a few short-lived exceptions. The financial crisis in 2008, starting with the collapse of Lehman Brothers, dramatically aggravated this situation. The construction industry, small-scale manufacturing, middle-sized firms and the export sector were hard hit in many countries which led to a sharp decline of tax revenues for the public authorities. While several countries from the Northern "hemisphere" of the EU have been faring relatively well in terms of growth rate and unemployment ratio, most of the countries in the Southern "hemisphere" have undergone a phase of negative growth, rising unemployment and, as a reaction to this, general political discontent. This has led to outbreaks of violence but also to an atmosphere of disappointment and frustration on the part of those who were and still are seriously hurt by the economic downturn. The countries most affected started to take, more or less successfully, measures to cut public spending. At the same time, higher taxes were introduced in order to prevent that public deficits reach intolerable heights.

Both the cuts within the welfare system and the increase in taxes were also required by other members of the currency union as a precondition for financial assistance to prevent an even more severe financial deterioration. These measures raise a general issue, namely, who should carry the burden of all this? There are at least two aspects to consider, a within-country perspective and an outside view held by other members of the currency union. In this paper, we shall focus on the former perspective, the innercountry situation. Should all income groups of society in the crisis-ridden countries contribute to a reduction and consolidation of the public budget? And even if there is agreement on this question, how should the corresponding shares be determined?

Greece probably is the most prominent example of a programme of austerity that immediately affected its population via cuts in unemployment benefits, pensions, tax increases and the cut-back of other financial transfers. These cuts were, however, carried out at a relatively high level, at least when compared with the levels in various other countries within the monetary union which were also forced to turn to a policy of severe cuts. People in Greece and in other South-European countries are stakeholders whose position is, understandably, tainted by self-interest. One should, however, keep in mind that the consequences of the various policy measures taken are much more perceptible to the population in these countries than to citizens in better-off economies who at this point mainly suffer from interest rates on savings that are close to zero per cent. The views of the people in the latter countries, of course, matter as well. Many of them fear that at some point, they will be the ones who, with their own tax money, have to foot the bill when public debt can no longer be expected to be paid back by the high-deficit countries. Important as this aspect is in relation to the question of viability of the Euro currency union, we will not consider it any further. Again, our focus will be on the problem of burden-sharing in the ailing countries, viz. in Southern Europe and Ireland. 
Theoretical and empirical studies on economic inequality have been the topic of several scholars during the last decades (see e.g. Amiel and Cowell 1999; Engelmann and Strobel 2004; Carlsson et al. 2005). In the social choice literature situations of allocating burdens are called "claims problems". This is somewhat different to the typical scenario of a bargaining problem where agents come together in order to jointly bring about an outcome which is supposed to be superior to their individual initial position, the cooperative surplus, and which each of them would not have been able to achieve just by his or her own productive effort alone.

Most generally a claims problem is completely described by the vector of relevant claims and the amount of resources to be allocated among claimants. The theoretical literature aims at identifying well-behaved rules, which determine for every claims problem a division of the amount available among the individuals (see Thomson 2003 for an overview). Different division schemes proposed in the literature include the proportional rule, which aims at proportionality of awards and losses, the constrained equal awards rule (CEA), which distributes the available resource evenly as long as no individual receives more than what she claims, and the constrained equal losses rule (CEL), which equalizes losses under the constraint that nobody ends up with a negative amount. These rules are sometimes called the "three musketeers" (Herrero and Villar 2001). A fourth classical solution is the Talmud rule proposed by Aumann and Maschler (1985) which rationalizes allocation situations found in the Talmud. All these rules, and several more, have been characterized axiomatically (see e.g. Bosmans and Schokkaert 2009; Thomson 2011, 2013). Since our focus is on loss sharing, a reference to contributions which explicitly deal with lower bounds is warranted (Thomson 2013, 2015). Moreno-Ternero and Villar (2004) introduce a property called securement which guarantees a minimal share to each person and they use this notion to characterize the Talmud rule. This property can be considered as a weakening of the concept of lower bound introduced by Moulin (2002). In this context, one should also refer to so-called equal-sacrifice rules characterized by Young (1988) and generalizations of this notion, namely generalized equal-sacrifice rules, introduced by Chambers and Moreno-Ternero (2016).

With respect to the claims problem in general, three interesting empirical investigations have recently been published. First, in questionnaire experiments conducted by Bosmans and Schokkaert (2009), students in Belgium and Germany faced allocation problems in the context of the division of revenues and the distribution of pensions. The authors varied both the amount to be divided and the degree of inequality of the claims vector. Allocations offered in the questionnaire were in accordance with various different rules known from the literature and, depending on the specific situation, have been classified by the authors as egalitarian (for example, constrained equal awards), neutral (e.g. proportionality rule) and anti-egalitarian (e.g. constrained equal losses). Their results showed strong support for the proportional rule in both contexts. In contrast, the constrained equal awards rule and the constrained equal losses rule received much less support, while other progressive solutions garnered some attention.

Second, Herrero et al. (2010) used both laboratory experiments and questionnaire investigations to gain further insights into the acceptance of the three prominent rules described. In the study four hypothetical situations were presented. Participants had to imagine a bank going bankrupt. Correspondingly, claimants were shareholders, 
depositors, or non-governmental organizations. In a fourth context the problem was framed in a neutral way. Again, the proportional rule served as a convincing coordination device in the lab and was also accepted by a larger majority of questionnaire respondents. Furthermore, the authors could detect a remarkable sensitivity towards the context within which the situations were presented to participants.

Third, Gächter and Riedl (2006) also considered the attractiveness of the "three musketeers" and a simple rule called "equal-awards". They conducted laboratory experiments and questionnaire studies. In the experiments participants had to negotiate with another individual about the division of a given amount of money. The authors constructed two different decision problems with distinct degrees of inequality with respect to the claims. In each situation, individuals were assigned to either group of claims on the basis of their results in a knowledge quiz. The bargaining process was "free-form": participants communicated with the help of computers and had to reach agreement within a given time limit. Without an agreement they received nothing except their show-up fee. The same decision problem was described in a questionnaire. Participants from different samples had to state which allocation they viewed as "fair". Yet another group of subjects faced the same problem but received descriptions of different rules and corresponding outcome in the specific situation. These participants were asked to rank the rules according to their attractiveness.

Gächter and Riedl report several results. Most importantly for the present study, they found the proportional solution to be the most attractive in the questionnaire studies, and this result held irrespective of whether respondents were asked to state the fair solution or to rank different rules that were described, while negotiation agreements were closer to the constrained equal awards rule. The authors explain these disparities by pointing out that the proportional solution is an attractive focal point without negotiation where the normative aspect comes to the fore, whereas the symmetric disagreement payoff in the bargaining experiment is zero to each person. This might have highlighted the attractiveness of more equal solutions. Furthermore, negotiators were forced to find compromise solutions in order to avoid a zero payoff.

Nevertheless, it should be pointed out that especially in the experiments by Gächter and Riedl participants bargained over some additional money, even though it turns out to be less than expected, while in our problem of burden sharing different income groups are thought to claim to be exempted from further tax payments. The importance of this difference was already pointed out in a study by Schokkaert and Overleat (1989) who conducted questionnaire experiments on the perception of justice in micro-level production contexts. Based on the observation that respondents reacted differently towards gains and losses, their results suggest that surplus sharing and cost sharing models have to be distinguished. Furthermore, the authors argue that acquired rights are important in the way that subsequently imposed income reductions are perceived differently compared to immediate losses.

In the following sections, we shall report our findings on burden-sharing in relation to questionnaire investigations that were run in countries that were particularly hard hit both economically and financially. It was our expectation that respondents in those countries would be well acquainted with the economic and social problems surrounding them and would therefore take our questionnaire study seriously. The countries 
from which we were able to gather empirical data were Cyprus, Greece, Ireland, Italy, Portugal, and Spain.

The structure of the rest of this paper is as follows. In the next section, we shall explain our questionnaire experiment ("rules" for the proceeding of the experiment and the full text of our questionnaire are relegated to Appendices A and B, respectively). In this section, we shall also briefly report findings from pilot studies, the genesis of our investigation so to speak, that we did at universities in Germany, Italy, and Spain (corresponding results are summarized in Appendix C). In the third section, we report the descriptive statistics for all six countries included in the final sample, statistically verify several hypotheses and present some regression results. In the fourth section we offer a general discussion of our findings and a few concluding remarks.

\section{Methods}

\subsection{The questionnaire}

Our study exhibits several typical characteristics of survey-based experiments in the realm of empirical social choice, i.e. student participants face hypothetical allocation problems and have to select from a set of theory-based allocations (see Gaertner and Schokkaert 2012, especially chapter 2 for a thorough discussion of the method). More concretely, the respondents were invited to imagine a country whose government is forced to levy additional taxes on its citizens for the coming years. The reason for this measure is that the country slipped into a financial crisis which led to a large budget deficit. It is assumed that there are five income groups of equal size in this country. Before the crisis began, the average monthly net income per income group was, in monetary units, $600,900,1500,2400,3600$, so that the aggregate income came up to 9000. The amount of additional revenue that the government now has to raise each month is 1800 . The students were then invited to decide in which way this sum should be split up among the different income groups. In order to help the students in their decision, various proposals were offered which specified the income distribution after the introduction of the additional tax. The respondents were asked to indicate which of the proposals came closest to their own view. They were also given the chance to propose their own tax scheme if they were unable to agree to any of the proposals. It was made clear that for each of the proposals offered, the officially determined minimal income of the country was lying below the lowest income within each tax scheme. The students were given room for personal comments and were asked to document some socio-demographic characteristics at the end of the questionnaire investigation. The different proposals that were offered in the final questionnaire were based on the following schemes (see Table 1):

(A) a taxing scheme analogous to the constrained equal losses rule;

(B) a proportional scheme (with a fixed tax rate of $20 \%$ );

(C) a scheme of progressive taxation (1);

(D) a scheme of progressive taxation (2);

(E) a scheme analogous to the constrained equal awards rule; 
Table 1 Allocations offered in the final questionnaire

\begin{tabular}{|c|c|c|c|c|c|c|c|c|c|}
\hline \multirow[t]{3}{*}{ Group } & \multirow[t]{3}{*}{ Net income before the crisis } & \multicolumn{8}{|c|}{ Net income after the introduction of the additional tax } \\
\hline & & \multicolumn{8}{|c|}{ Proposals } \\
\hline & & (A) & (B) & (C) & (D) & (E) & (F) & (G) & Own proposal \\
\hline 1 & 3600 & 3240 & 2880 & 2700 & 2500 & 2100 & 2736 & 2520 & \\
\hline 2 & 2400 & 2040 & 1920 & 1900 & 1900 & 2100 & 1824 & 1680 & \\
\hline 3 & 1500 & 1140 & 1200 & 1250 & 1350 & 1500 & 1140 & 1500 & \\
\hline 4 & 900 & 540 & 720 & 800 & 860 & 900 & 900 & 900 & \\
\hline 5 & 600 & 240 & 480 & 550 & 590 & 600 & 600 & 600 & \\
\hline Sum & 9000 & 7200 & 7200 & 7200 & 7200 & 7200 & 7200 & 7200 & \\
\hline
\end{tabular}

(F) a scheme that exempted the lowest two income groups and taxed the upper three groups proportionally;

(G) a scheme that exempted the lowest three income groups and taxed the upper two groups proportionally.

Note that schemes (C) and (D) both satisfy progressivity and income order preservation. If $y_{i}$ and $y_{j}$ are taxable incomes of two persons $i$ and $j$, and $R_{i}$ and $R_{j}$ are the taxes to be paid by $i$ resp. $j$, then progressivity means that if $0<y_{i} \leq y_{j}, R_{i} / y_{i} \leq R_{j} / y_{j}$. Income order preservation means that for each pair $i, j$, if $y_{i} \geqslant y_{j}, y_{i}-R_{i} \geqslant y_{j}-R_{j}$. Both properties together imply inequality reduction (Ju and Moreno-Ternero 2008). An easy calculation shows that the post-tax income profiles of both schemes Lorenz dominate the original income profile.

Furthermore, while the first four schemes levy additional taxes on all income groups, schemes $(\mathrm{E}),(\mathrm{F})$, and $(\mathrm{G})$ exempt the lower two, respectively three groups from any additional contribution. This property relates to the notions of lower bound and securement exposed in various papers by Moulin, Moreno-Ternero and Villar to which we referred in the introduction.

\subsection{The genesis of our study}

The final questionnaire text as well as the set of proposals have been specified on the basis of pilot studies at universities in Germany, Italy, and Spain. In different preliminary versions various theory-based proposals were tested for their potential support. All results are reported in Tables 9, 10,11 and 12 in Appendix C. The hurried reader may safely skip this part but we think that it will help to understand how we arrived at the final set of questions that we gave to the students.

Our very first questionnaire already contained, among other proposals, schemes A, B, E, F, and G from Table 1 above (see Table 9). At Halle University, out of 106 respondents, $34.9 \%$ picked the proportional rule and $30.2 \%$ chose rule $\mathrm{F}$ which may be interpreted as some kind of progressivity though the upper three groups are taxed proportionally. The other schemes only received minor support. An explicit progressive scheme, however, was not (yet) offered. 
In a second step, we added a progressive taxation scheme to the already existing options, and this progressive scheme immediately received strong support from respondents at universities in Osnabrück, Seville, and Rome. In Osnabrück, where we had 85 respondents, the progressive rule (scheme $\mathrm{C}$ in Table 1 above) garnered $54.1 \%$, the proportional rule received $14.1 \%$ and rule $F$ (i.e. rule $\mathrm{G}$ in Table 10) was favoured by $12.9 \%$, with the other schemes well below the latter percentage. The results in Seville, where we had 67 respondents, were similar to Osnabrück. The progressive scheme reached $43.3 \%$, the proportional rule 6.\% and rule F from Table $116.4 \%$ (see Table 11). Finally, out of the 33 participants in Rome $42.4 \%$ opted for the progressive scheme while rule $\mathrm{F}$ from Table 1 gained $21.2 \%$ (Table 12).

Nevertheless, several students participating in the pilot studies proposed allocations which reflected different versions of progressivity so that we then decided to include two schemes with different degrees of progressivity, namely schemes C and D, to control for differences in the acceptance of such rules (see again Table 1 above).

Is it possible that rules $\mathrm{B}, \mathrm{C}$, and $\mathrm{D}$ received more support than the other schemes because they were placed somewhat in the middle, as one might ask? We do not think so. First of all, the scheme based on CEA is also "somewhat in the middle" but received little acclaim in pilot studies but also in the final questionnaire study, while scheme F garnered considerable support in several of the locations. We did not try to randomize the order of options. Our array of alternative schemes from left to right is in a certain sense systematic, namely scheme A, for example, is the worst for the "poorest" and the best for the "richest", while rules E to G are best for the lowest two classes. We intended to facilitate the students' task which is non-trivial.

Before we turn to the analysis and results of the final study, we should also mention that we excluded three further questionnaire studies. One was conducted in Patras, Greece, among 19 philosophy students whose answers were amazingly close to those of the students in Athens reported in the next section. Then we excluded the findings among 27 students who study journalism in Madrid (Carlos III). These students "disliked" the proportional rule as much as the students in Athens but had, in contrast to Athens, a very strong preference for the first of the two progressive schemes. We decided to exclude these groups for two reasons. One was the relatively low sample size in each case; the second and more important reason was the fact that the fields of study of these respondents are very different from economics and business administration. In further investigations, it would, of course, be interesting to see how, if at all, students from different backgrounds differ in their evaluations. Finally, we decided to exclude very recent findings from Barcelona (Universitat Autònoma). These were done in May 2015 while all the other studies were run between October and December of 2014. For Barcelona, we have results from first year $(n=52)$ and third year $(n=33)$ students in business administration. Both groups hardly chose the proportional rule. While the first year students clearly preferred the more progressive scheme to the less progressive version, the third year students just stated the opposite preference, also distinctly. This is another aspect within the context of burden sharing worth exploring in future research. 


\subsection{Analysis}

We will analyse our final data set in four steps and formulate corresponding hypotheses. First, we look at the descriptive data of the total sample and of each country separately. The main focus is on the performance of the proportional rule, which, as mentioned above, received overwhelming support in previous experimental studies. Furthermore, we are interested in the support for various other schemes that result from different theoretical conceptions. In order to compare support rates, we calculate 95\% confidence intervals based on bootstrapping procedures for the most relevant allocations. The absence of overlap between confidence intervals compared indicates that the two corresponding rates are significantly different from each other.

Second, we turn to potential local differences in more detail. Although all countries involved have been hit by the financial crisis, their citizens may have been affected at different paces and may have experienced distinctly different consequences. Furthermore, it is well-known from other studies that in general country-specific differences in attitudes towards redistribution exist (see e.g. Gaertner and Schokkaert 2012, chapter 3 ). Hence, it is important to investigate such disparities in the light of the present theme, the financial crises and the issue of burden-sharing. In order to compare response distributions of answers on allocation proposals between pairs of samples we apply $\chi^{2}$ tests.

Third, each proposal can be characterized by a specific degree of inequality of the resulting income distribution. Hence, we calculate for all proposals the corresponding Gini coefficient and use it as a dependent variable in an OLS regression model. Here, the vector of explanatory variables contains place indicators but also socio-demographic characteristics of respondents including age, gender, income of the family in which the respondent grew up, expected income in 10 years, and political attitude (see again Appendix B for corresponding questions). These characteristics should help us to control for basic socio-demographic differences. Furthermore, to analyse factors influencing the choice of the proportional solution as a central research question of this study, a binary logistic regression model is estimated including again the explanatory variables just described. Finally, we focus on the three most prominent schemes in all of our surveys and run a multinomial logistic regression model.

Fourth, to explain differences between answers from different places we consider two potential reasons and evaluate their explanatory power in two modified OLS regression models for the Gini coefficients which correspond to the answers of the respondents. Here we substitute the place indicators mentioned above by alternative macro variables. On the one hand the current economic performance of each country may influence answers of respondents. We use the quarterly rate of unemployment as a proxy for various aspects of the economic situation of a country. Unemployment rates are constantly reported in the media and may therefore act as an important point of orientation or reference in the respondents' minds. On the other hand, the redistributive effect of the tax system in the participant's own country could explain answers in the way that respondents just "confirm" the system in which they live. Miller (1992), for example argues that studying beliefs about "macro-justice", i.e. justice across the entire society, faces the risk that respondents are biased by the current income distribution and welfare practices of their own society. Hence, to catch at least a glimpse of such effects 
we relate real Gini coefficients before and after taxes by calculating the Musgrave-Thin index (Musgrave and Thin 1948) which then serves as an alternative macro variable. However, it has to be pointed out that the results should be considered very cautiously since more data from more than six countries would be necessary to substantiate the findings.

For all logistic regression models, we report marginal effects to give an impression of the strength of the effects observed. In each case, variance inflation factors (vif) are calculated to evaluate the severity of multicollinearity. A value above 5 would suggest a problem (Sheskin 2011), but in our case they are always clearly below this threshold. All analyses have been conducted with the software packages SPSS ${ }^{\mathrm{TM}}$ (version 22) and STATA $^{\mathrm{TM}}$ (version 12).

\subsection{The experiment}

The questionnaire experiment was run at seven universities in six different countries which were hit by the crisis. An overview of the different places, the timing of the studies and sample sizes is provided in the upper part of Table 2. All surveys were conducted in undergraduate business administration or economics classes during lecture time. In order to focus on one specific difference between respondents-in our case the country where they currently live - it is an advantage to focus on individuals of almost similar age, equivalent education and potentially comparable professional aims. Additionally, we regard it as essential to control for influences of major political or economic events in the Euro-area during our investigation so that we tried to conduct the studies at similar periods of time at all places.

At the beginning of the experiment students received a general introduction. The text provided in Appendix A was read out aloud by the corresponding lecturer and presented on PowerPoint slides. With the help of these instructions we tried to signal that students should take this experiment seriously and state their "true" choice of the preferred allocation. Also, we guaranteed that participation was voluntary and anonymous. Students could cancel their participation in the experiment at any time or leave some questions unanswered.

After collecting the questionnaires, the completed sheets were sent to us by post. All questionnaires were recorded and statistically analysed in Germany. Afterwards, all preliminary results were sent back to each colleague who helped us in this investigation in order to give students some feedback on their decisions, in particular to enable them to compare their own response with those from others at their university and with those of respondents from the other countries involved.

\section{Results}

At the beginning, we excluded those students who had not completely answered both the decision problem and the demographic questions. In Table 2 resulting drop-out rates and reduced sample sizes are stated. Obviously, all those respondents had to be excluded who rejected to state any allocation proposal, but answered at least one of the socio-demographic questions or gave us some written comments. This group 


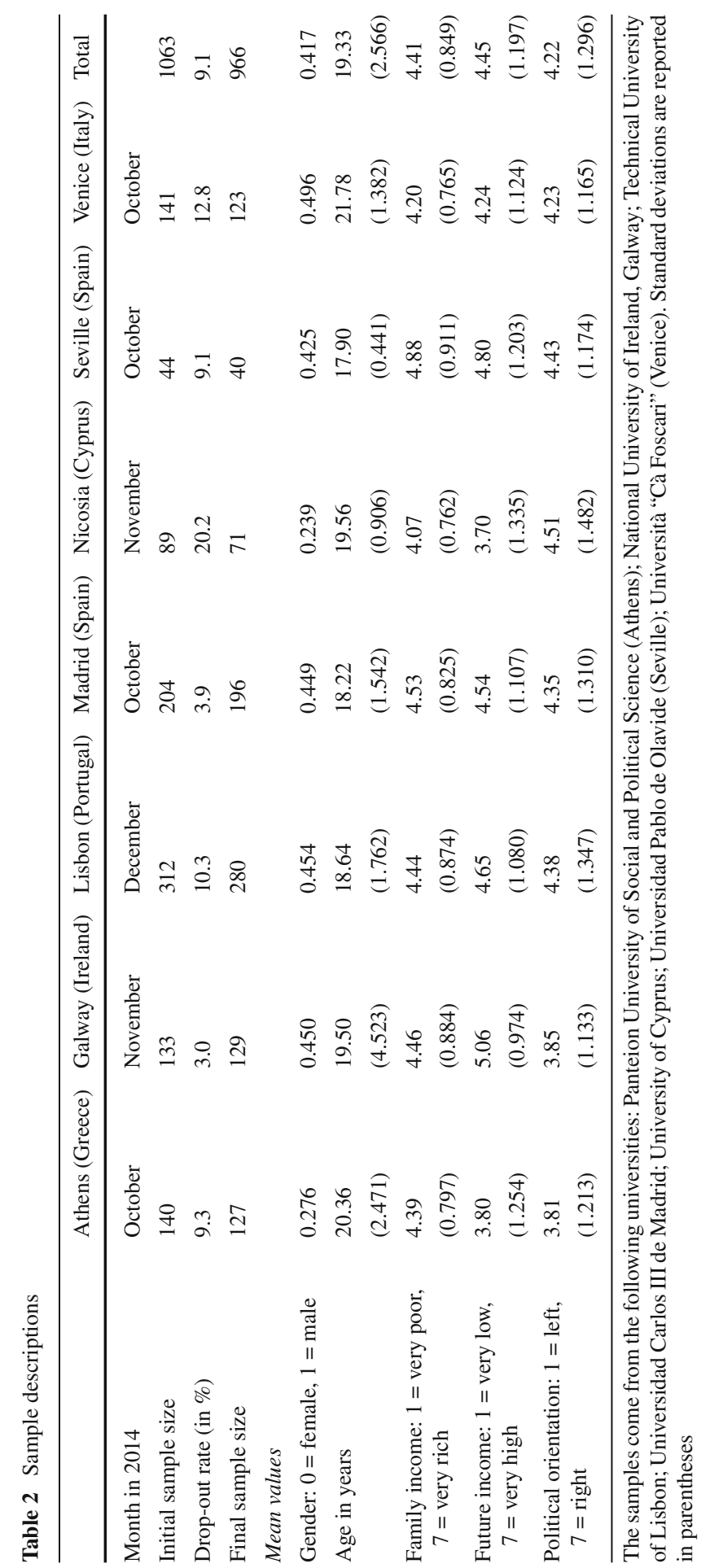


comprised 19 students, i.e. $1.8 \%$ of all participants. Next, we also omitted all cases in which at least one socio-demographic answer was missing. The largest proportion of exclusions, about $5 \%$ of the remaining cases, was inter alia based on missing answers to the question on students' political attitudes. However, as these individual characteristics are crucial for further investigations of local differences, completeness is important here. Finally, we further excluded 14 students with individual proposals that did not yield the exact amount needed to be raised by the government in the hypothetical situation, since these responses would be difficult to interpret.

We extensively checked whether any of these exclusions had an impact on results. As can be seen from the values stated in Table 2, drop-out rates differ between the places involved. Thus, $\chi^{2}$ tests were used to compare the distribution of answers on the different proposals between individuals with some missing demographics and those with complete answers. In neither case could we detect any significant difference.

Additionally, the questionnaire contained an item regarding changes of political attitudes in the last 5 years. Obviously several students had problems with this question and ignored it. Hence, we decided to omit the question from further investigations. Only about $15 \%$ of those respondents, who answered this question, stated that their political view had changed.

Also from Table 2 it can be seen that there is not much variation among different places with respect to socio-demographic characteristics. But there are a few exceptions. On average students from Seville are almost 3 years younger than those from Venice. A t-test on mean values confirms that these differences are statistically significant at the $1 \%$ level. Furthermore, while there is only some variation with respect to family income, which confirms that respondents may have a similar economic background, at least on average future income expectations differ. They are lowest in Athens and Nicosia and highest in Galway. In fact, mean income expectations are significantly lower in Athens and Nicosia than at each of the other places. It is likely that these anticipations reflect the perceived current economic situations in Greece and Cyprus. However, it is remarkable that with regard to political orientation students from Athens are more to the left, while their counterparts from Nicosia are more to the right. Again, this difference is statistically significant.

\subsection{Descriptive results}

A first look at the answer frequencies presented in Table 3 shows that there is quite a lot of similarity in relation to all countries. More specifically, only three of the seven proposals that we had offered garnered wider support. These were the proportional solution (scheme B) and the two progressive taxation schemes (rules C and D), although within this "trio", there are major differences to which we come back in the following paragraphs. There is a stunning similarity among the responses from Madrid and Seville indicating no significant differences with respect to these two sites from the same country.

In general, the impression of large similarity is also due to conformity in relation to schemes $\mathrm{A}$ and $\mathrm{E}$ to $\mathrm{G}$. All these proposals were favoured by only smaller numbers of respondents. This assertion also includes the percentage of students who seized the 


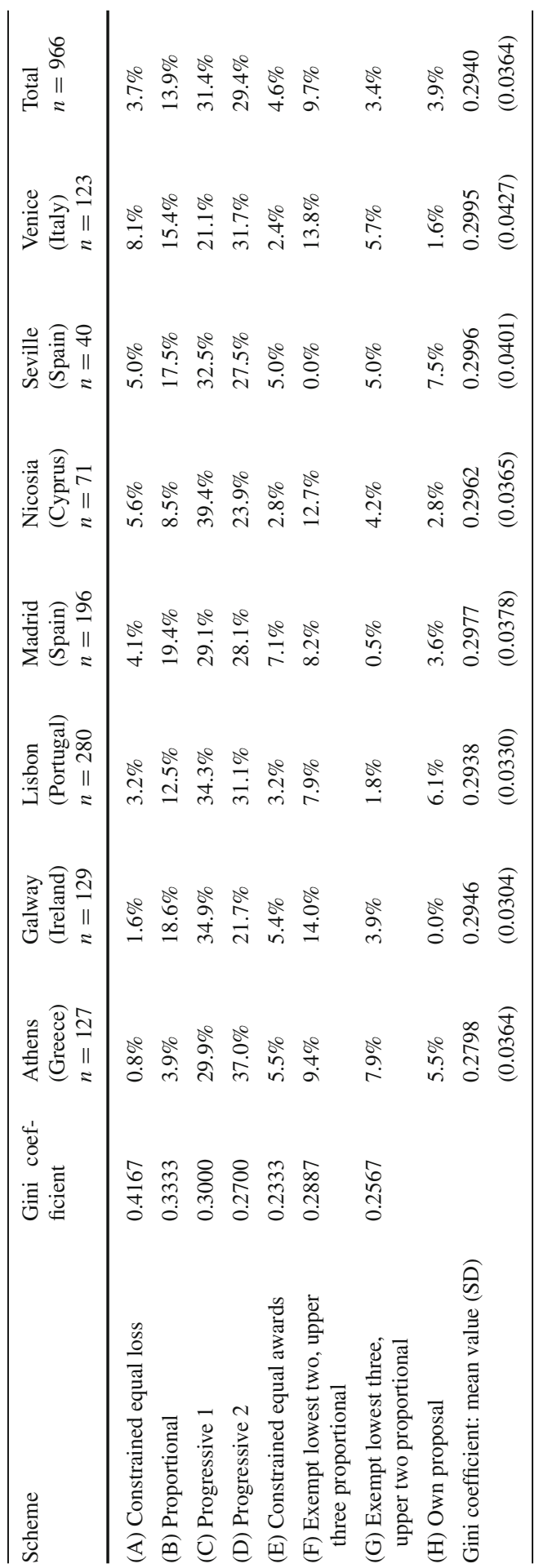


opportunity to propose their own solution to the loss-sharing problem. There is one exception, however, which is worth mentioning. Proposal F which exempts the two lowest income groups and burdens the remaining layers of society proportionately received non-negligible support in six of the seven universities, again a feature that adds to the impression of similarity. In some sense, this proposal can also be considered as progressive since there is no burden sharing at all for the two lowest groups.

Turning to major dissimilarities between places, our main question concerns the relationship between the proportional rule and the two progressive taxation schemes. In our introduction, we mentioned that the proportional rule had won much support in various other investigations.

Result R1: In all countries involved the proportional rule is less frequently chosen than the two progressive schemes taken together.

In Table 4 we report again the relative frequencies of the three most often observed choices, viz. proportional and the two progressive schemes. In order to compare the different values for each place, we calculated $95 \%$ confidence intervals based on bootstrapping procedures. Hence, the absence of overlap between compared confidence intervals indicates that the two relative frequencies are significantly different from each other.

The assertion in R1 holds for the complete sample of seven universities, and it is also true for each of the universities individually. Even more striking, for the total sample, but also for respondents in Athens and Lisbon, this statement is true in a pairwise comparison between the proportional scheme and each of the two progressive proposals. Additionally, it also holds for Galway and Nicosia in relation to the less progressive scheme and for Venice with respect to the more progressive rule. It is worth noticing that the proportional scheme was particularly unpopular at the universities in Greece and Cyprus. To summarize, the solution in accordance with the proportional allocation of losses clearly finds less support than the two progressive schemes among all groups of students included in our sample.

Could it be that the proportional rule was less frequently chosen because it was not easily recognized as being proportional? We do not believe that this could have been the case. First of all, the deduction of $20 \%$ from the status quo net income can easily be detected (and calculated) at least for groups 3-5. We find that the two progressive schemes are much more complex in their structure. The main reason, however, that the proportional rule did not have an a priori disadvantage against other schemes has already been given in Sect. 2.2. In our very first pilot study, where, as mentioned, we offered neither scheme $\mathrm{C}$ nor rule $\mathrm{D}$, the proportional rule received by far the strongest support among all schemes that were offered.

There is a further point to be made in this context. It was on purpose that we did not tell our students anything about the theoretical concept underlying each of the seven schemes. To talk about proportionality or progressivity or a rule of equal losses, for example, might have triggered certain reactions so that a shade of manipulation, into one direction or another, could, perhaps, have entered the evaluative exercise, something which should be avoided by all means. We rather thought that students should compare different distributions of net income after additional taxes had been 


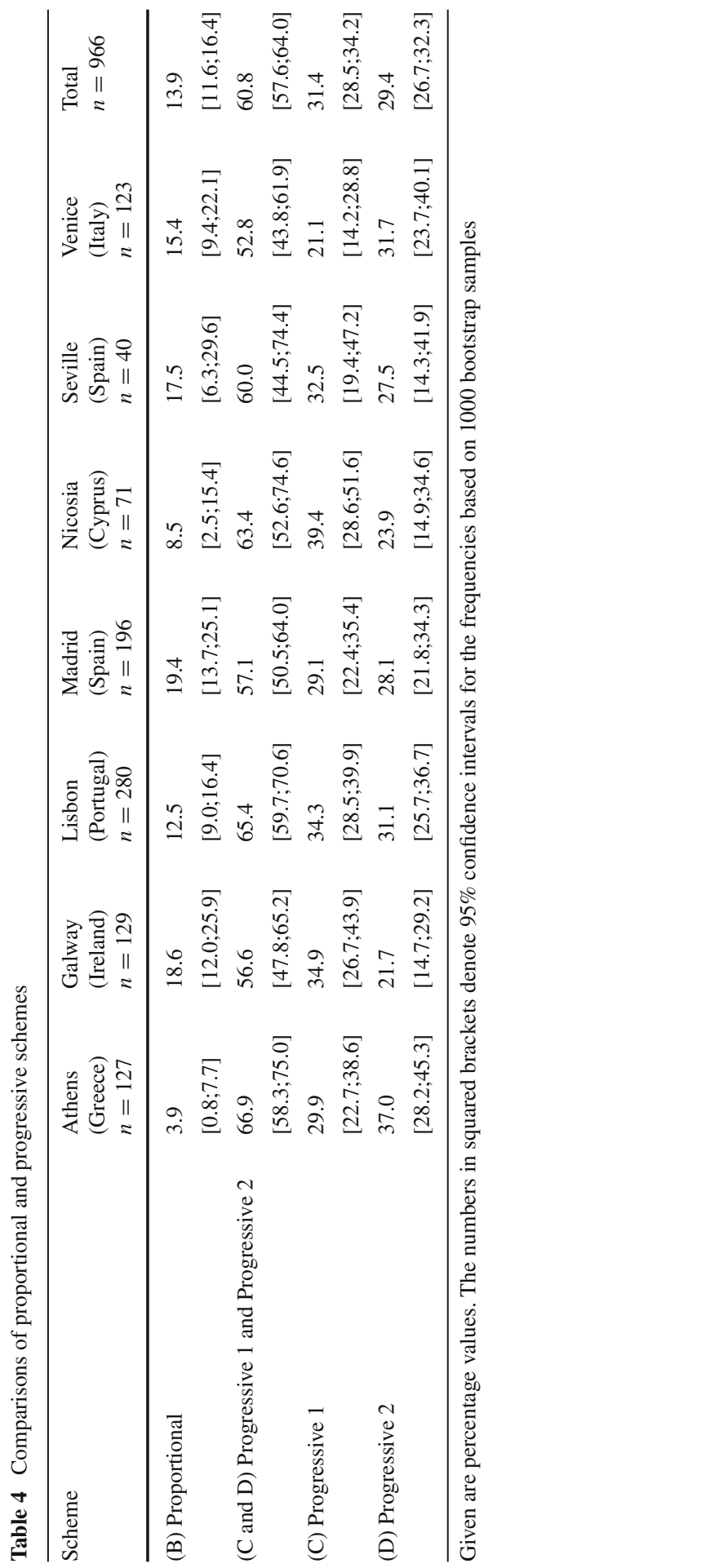


levied and then make their choice. Actually, several of the verbal answers that we received lean into this direction.

\subsection{Country-specific answers}

The descriptive results discussed in the previous subsection have already revealed some country-specific differences. Our next question focuses on the distribution of the most frequently chosen proposals, namely the proportional rule (B) and the two progressive schemes ( $\mathrm{C}$ and $\mathrm{D})$, and tries to differentiate among different sites.

Result R2: The distribution of proposals B, C, and D for Greece (Athens) differs from the one for the other Southern European countries plus Ireland.

In Table 5 we focus only on those respondents who selected one of these three schemes. Their share of the corresponding total sample at each location mildly varies between $68.3 \%$ in Venice and $77.9 \%$ in Lisbon. Nevertheless, we regard it as important to exclude any effects resulting from different frequencies of choices apart from the three schemes which may then dilute the following $\chi^{2}$ tests. The numbers stated in the table show that result $\mathrm{R} 2$ can be confirmed due to two findings: first, respondents in Athens picked the proportional solution significantly less often than students at the other universities. Second, respondents in Athens chose the more progressive of the two progressive schemes considerably more often than students at the other sites and at the same time picked the less progressive proposal with roughly the same frequency as students at the other locations.

Table 5 Proportional and progressive taxation schemes (only schemes B, C, and D): comparison of places

\begin{tabular}{llllllll}
\hline & Athens & Galway & Lisbon & Madrid & Nicosia & Seville & Venice \\
\hline Sample size & 90 & 97 & 218 & 150 & 51 & 31 & 84 \\
$\begin{array}{l}\text { Proportion of total } \\
\quad 70.9\end{array}$ & 75.2 & 77.9 & 76.5 & 71.8 & 77.5 & 68.3 \\
sample (\%) & & & & & & & \\
(B) Proportional (\%) & 5.6 & 24.7 & 16.1 & 25.3 & 11.8 & 22.6 & 22.6 \\
(C) Progressive 1 (\%) & 42.2 & 46.4 & 44.0 & 38.0 & 54.9 & 41.9 & 31.0 \\
(D) Progressive 2 (\%) & 52.2 & 28.9 & 39.9 & 36.7 & 33.3 & 35.5 & 46.4 \\
$\chi^{2}$ test statistic & & & & & & & \\
Athens & - & $17.615 * * *$ & $7.676 * *$ & $15.737 * * *$ & $5.286 *$ & $8.087 * *$ & $10.967 * * *$ \\
Galway & $17.615 * * *$ & - & $5.030 *$ & 2.079 & 3.487 & 0.486 & $6.572 * *$ \\
Lisbon & $7.676 * *$ & $5.030 *$ & - & $4.877 *$ & 2.020 & 0.848 & $4.649 *$ \\
Madrid & $15.737 * * *$ & 2.079 & $4.877 *$ & - & $5.890 *$ & 0.191 & 2.194 \\
Nicosia & $5.286 *$ & 3.487 & 2.020 & $5.890^{*}$ & - & 2.097 & $7.881 * *$ \\
Seville & $8.087 * *$ & 0.486 & 0.848 & 0.191 & 2.097 & - & 1.429 \\
Venice & $10.967 * * *$ & $6.572 * *$ & $4.649 *$ & 2.194 & $7.881 * *$ & 1.429 & - \\
\hline
\end{tabular}

Levels of significance: $* 10 \%, * * 5 \%, * * * 1 \%$. Each sample only includes answers in accordance with schemes (B), (C) or (D) 
In addition, we find two similarities between the results from Athens and corresponding findings from other locations noteworthy. On the one hand, support for the proportional solution is also very low in Nicosia compared to the remaining sites, where it is strongest in Galway and Madrid. On the other hand, only in Venice the more progressive scheme also finds much stronger support than the less progressive solution. At all the other locations, this ordering is reversed. Especially in Galway and Nicosia, the less progressive scheme is more often chosen than the other two solutions.

Result R3: Athens and Galway are "polar cases" if one restricts the analysis to the three most popular schemes B, C, and D, whereas findings at the other sites lie in between.

The $\chi^{2}$ tests also reported in Table 5 confirm the previous observations of the descriptive results. Here, pairwise comparisons between site-specific allocations of answers on the proportional and the two progressive schemes are conducted.

The results suggest, indeed, that Athens and Galway can be described as polar cases. The extreme position of Athens manifests itself most clearly in a direct comparison with Galway, Madrid, and Venice, respectively. Additionally, and in line with the descriptive results, the differences between answer distributions in Athens and Nicosia are statistically significant only at the $10 \%$ level $(p=0.071)$. Galway shows, of course, a substantial difference to Athens. In a comparison between these two sites, restricted to the proportional and the two progressive solutions, the $p$ value of the $\chi^{2}$ tests statistic is below 0.001 and is lowest among all values estimated in binary comparisons between any two places.

Furthermore, the difference is still significant between Galway and Venice ( $p=$ 0.037 ) or Lisbon ( $p=0.081)$, but there are no significant differences in relation to the other sites. Furthermore, the significant differences between Venice on the one hand and Athens and Galway as well as Lisbon $(p=0.098)$ and Nicosia $(p=0.019)$ on the other is mainly due to the polarisation of choices between no progression and higher progression in Venice. First, a large proportion of respondents in Venice opted for the proportional solution and this was accompanied by the fact that second, the more progressive scheme received substantially more support than the less progressive rule. We will further investigate country-specific differences in the following two subsections.

\subsection{Regression models with place effects}

As shown in Table 2, there are, among the sites incorporated in our investigation, some disparities with respect to several basic socio-demographic characteristics of respondents. Hence, to control for the influence of such attributes and to check the robustness of the results we estimated three different regression models already described in the second section. With regard to the place dummy variables, Athens serves as the base case in all models because the results previously presented indicate that this site is one polar case compared to the other locations.

First, we use the Gini coefficient as a dependent variable. This has the great advantage that we are able to compare each allocation chosen including individual proposals. Hence, every single distribution of losses is interpreted with respect to the resulting 
inequality among income groups. A higher coefficient of the OLS regression model indicates a higher average inequality brought about by the corresponding group of individuals.

In Table 3 it has already been stated that the mean Gini coefficient in Athens is considerably lower than the corresponding values at all other sites. The estimated coefficients for the different places reported in the first column of Table 6 convincingly confirm this observation while controlling for some socio-demographic differences between single places. Almost all coefficients are significantly higher than zero at the $1 \%$ significance level.

Second, turning to the choices in accordance with the proportional solution, Table 3 reveals again that the probability of observing a corresponding answer is lowest in Athens and highest at the sites in Spain, with Galway and Venice being close. The regression results of the binary logit model presented in the second column of Table 6 confirm these observations. The estimated marginal effects for Galway, Madrid and Venice indicate a higher probability of observing the allocation that reflects a proportional distribution of losses compared to the sample from Athens.

Third, we focus on the three most prominent schemes, viz. proportional, progressive 1 and progressive 2. Consequently, the total sample size is reduced from 966 to 721 respondents. In order to investigate differences with respect to the relative frequencies of choosing in accordance with the three rules we estimated the multinomial logistic regression model stated in the last columns of Table 6 . The place effects observed for the proportional solution are even more pronounced here compared to the binary logit model due to the sample reduction. Nevertheless, the marginal effects reported in all three columns also reveal further differences. The higher probability of observing a choice in accordance with the proportional rule in Venice compared to Athens leads to a lower probability for the first progressive rule. In some contrast, in Galway the higher probability for the proportional rule clearly results in less support for the second progressive scheme. The results from Madrid are less clear-cut. Hence, the identification of Athens and Galway as polar cases seems to be justified.

Result R4: Politically left-oriented respondents and those who expect a low future income are more in favour of a redistribution from the rich to the poor.

The individual characteristics incorporated in the regression models reveal some further effects which, however, mainly confirm basic intuitions. First, older respondents are less likely to choose in accordance with the proportional solution and more often favour the more progressive scheme. However, since the sample includes only students there is not much variation with respect to the age of respondents and the effect is small. Second, individuals who report an orientation toward the political left support on average a lower Gini coefficient and more often reject the proportional scheme. This confirms the intuition that left-leaning people more often support redistribution from the rich to the poor. Third, with respect to past family and future own income we observe in both logistic regression models that individuals, who expect to earn a lower income in the future, less often support the proportional solution and more often support the first progressive scheme.

Although the direction of the effect is not surprising and its size is reasonably high, we expected even some stronger results with respect to own income. Hence, we 


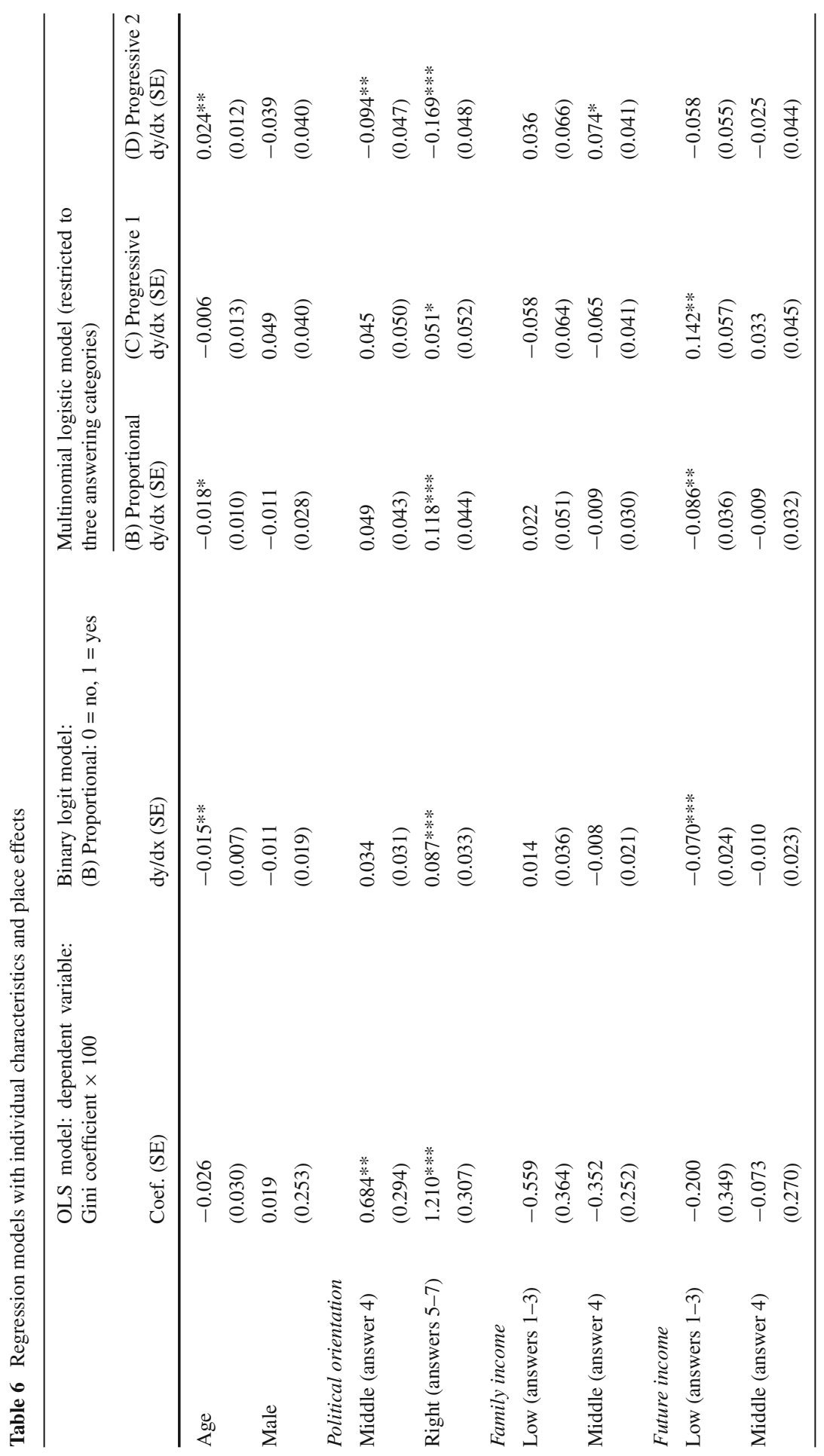




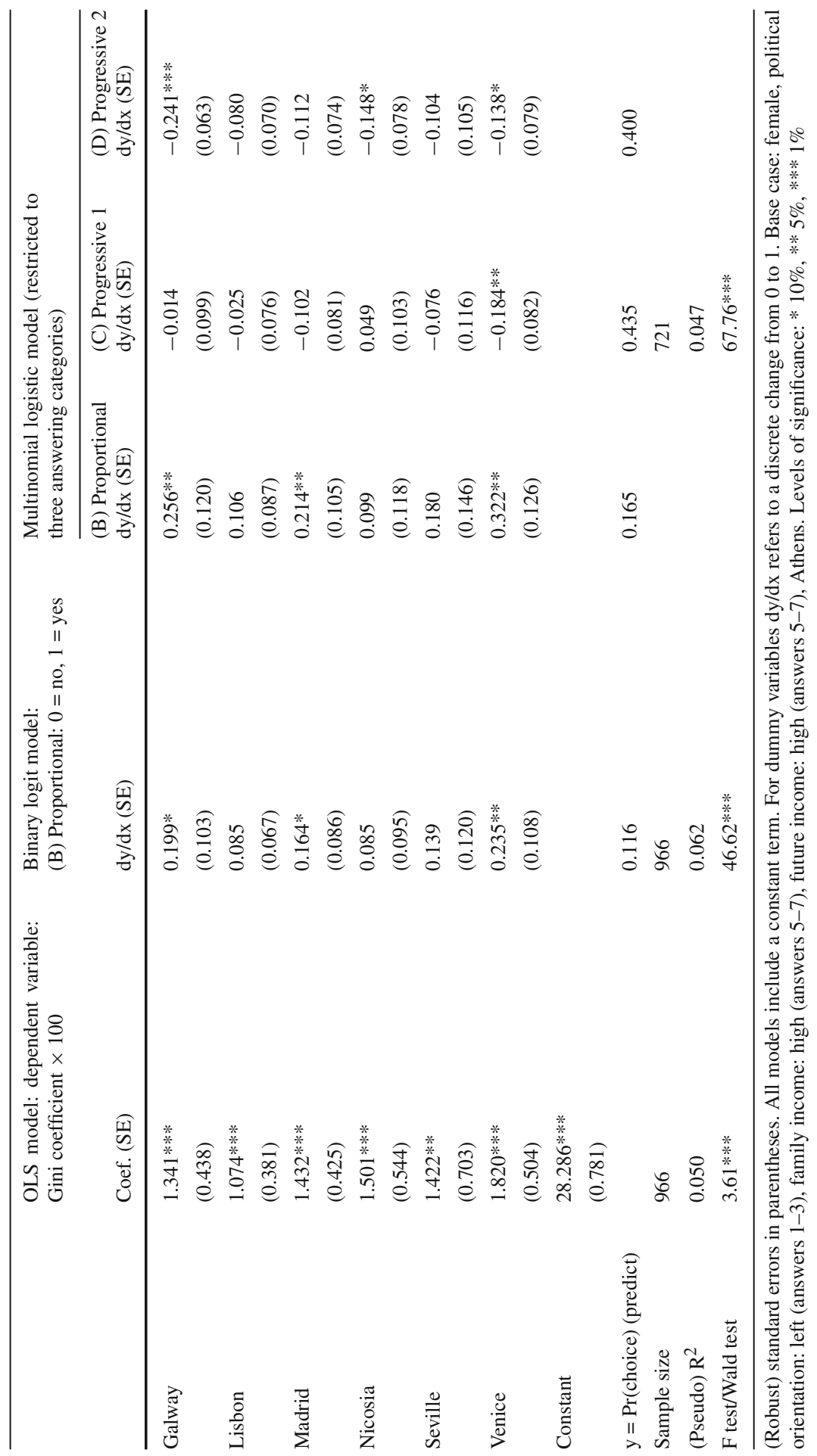


also tested whether changes in one's own income, i.e. a higher or lower future income compared to the past family income, has a more remarkable effect. However, we could not detect any significant influences.

Thus to summarize the findings of the regression models so far, we can confirm the main differences between places already observed from the descriptive data. However, having controlled for some socio-demographic characteristics we can show that our results are robust with respect to differences between samples regarding these individual attributes.

\subsection{Two macro indicators as potential explanations for place differences}

It is not utterly straightforward to explain especially the large difference between the results from Ireland and Greece described in Sect. 3.2. One could, of course, argue in terms of the current economic performance of the two countries which leads to optimism in one case and serious doubts in the other. As far as our own questionnaire data set is concerned, we finally consider two indicators of different sorts as potential explanations for country differences more generally.

Result R5: The unemployment rate has some explanatory power for the Gini coefficient resulting from the answers of respondents, while this is not the case for the Musgrave-Thin index.

The first explanation refers to the rates of unemployment for the quarters in 2014 (see Table 7). For Greece, the quarterly, seasonally adjusted figures are 27.1, 27.0, 26.2, and 25.9, for Ireland the figures are 12.2, 11.6, 11.1, and 10.4.

What is remarkable is that for Spain, the unemployment figures look very bad as well. As a matter of fact, these are almost similar to those in Greece. In contrast to Greece, however, the figures for family income 10 years ago and for the own expected income in 10 years' time are for our respondents in Madrid 4.53 and 4.54 and for Seville 4.88 and 4.80 . This subjective view is quite different from the judgment of the students in Athens (see again Table 2).

To control for such different aspects simultaneously we reconsidered the OLS regressions reported in Sect. 3.3, which allows for ordering all answers given by the students, but substitute the place dummies by the unemployment rates of each country determined directly before the questionnaire study, viz. in the third quarter of 2014. The resulting model is contained in the first column of Table 8.

The estimated coefficient for the rate of unemployment is negative and significant at the $5 \%$ level. Hence, a higher unemployment rate corresponds to a lower average Gini coefficient stated in the questionnaire by our respondents. This result is robust with respect to several quarters of 2014; the results are very similar if data from the second or fourth quarter of 2014 are used. Hence, for the entire sample, country-specific unemployment rates have predictive power for the desired distribution of burdens observed in the questionnaire.

The second potential explanation we consider for the place differences refers to the real tax progression. In Sect. 2.3, we have already explained that the answers of the students in the sample may reflect or confirm the existing progressivity of the tax system of their country. In the last columns of Table 7, we present relevant data from 


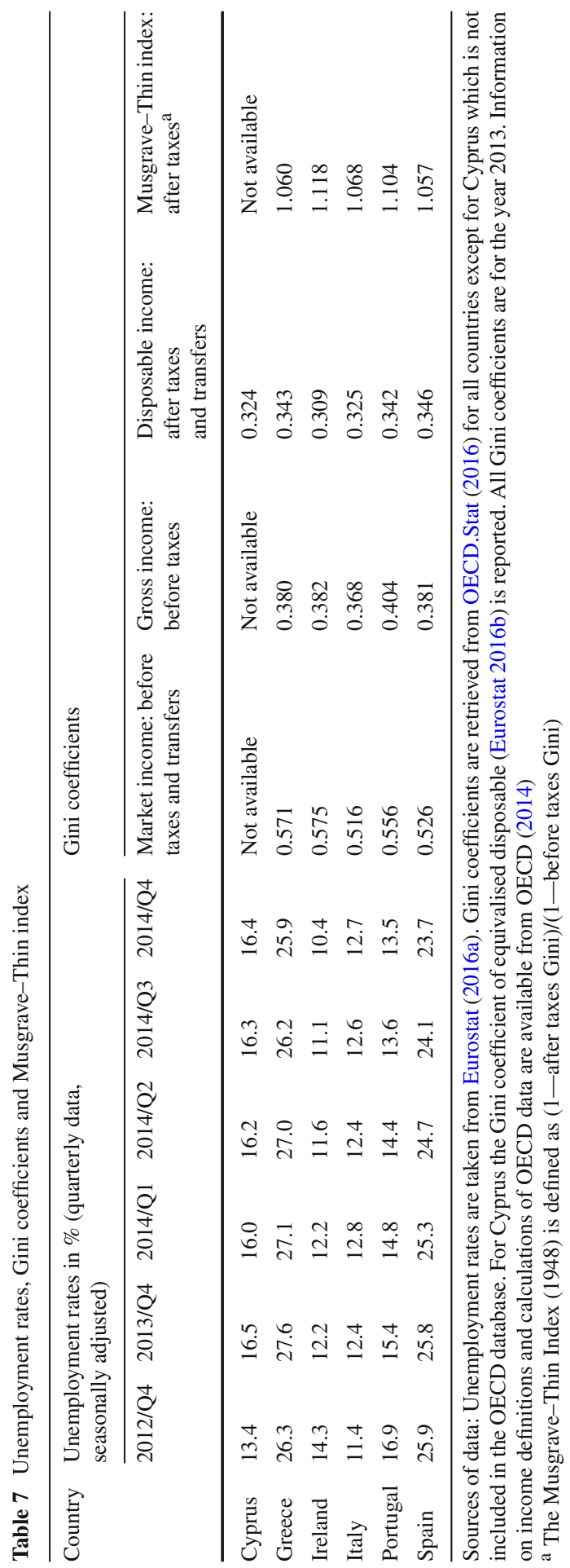


Table 8 Regression models with individual characteristics and macro effects
Robust standard errors in parentheses. Base case: female, political orientation: left (answers 1-3), family income: high (answers 5-7), future income: high (answers 5-7). Sample sizes differ because the Musgrave-Thin after taxes is not available for Cyprus. Levels of significance: * $10 \%$, ** 5\%, $* * * 1 \%$

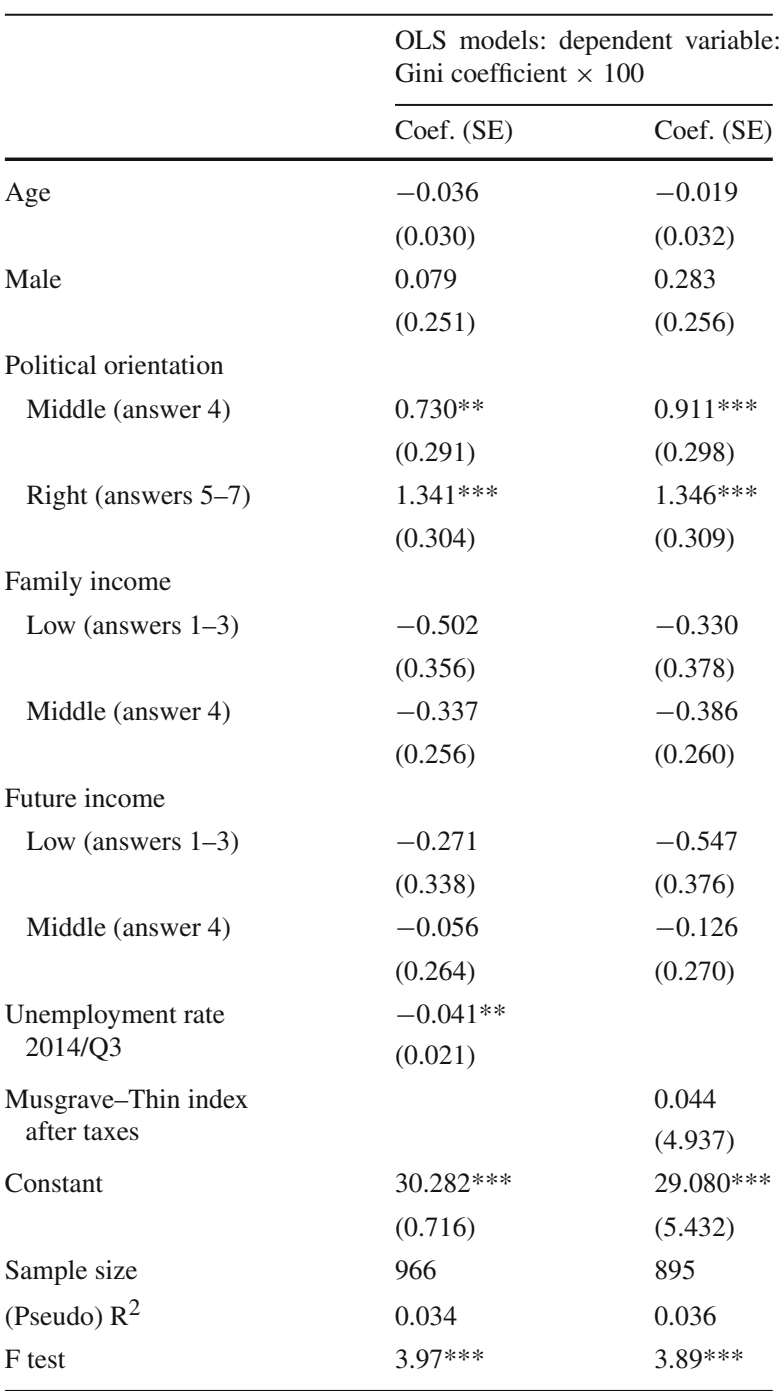

the OECD database for 2013, the last year for which all necessary values are currently available. Unlike other official sources, the OECD data differentiates between taxes and transfers, but unfortunately values for Cyprus are not contained. For each country we compare Gini coefficients before and after taxes and calculate the Musgrave-Thin index (Musgrave and Thin 1948). The index is higher if there is more redistribution due to taxes.

Following the hypothesis that respondents refer to the progressivity of the existing tax system, the Greek students would choose a less progressive rule than the Irish students according to the numbers in Table 7. This, however, is not in conformity with our results. The opposite is the case (see again the mean values for the Gini coefficients 
in Table 3). Furthermore, for the entire sample, the impact of the Musgrave-Thin index on the Gini coefficients resulting from the answers of our respondents is not clear as can be seen from the results reported in the last column of Table 8. The estimated coefficient is close to zero.

To summarize while the unemployment rate seems to explain some place differences observed, we could not find any significant relation between the real progressivity of the tax systems and the Gini coefficients corresponding to the answers in the questionnaire.

\section{Discussion and concluding remarks}

Background of this study is the present economic and financial situation of major countries in Southern Europe and Ireland which were hit after the collapse of Lehman Brothers in 2008. These countries as well as others had been forced to take severe measures in order to reduce their budgetary deficits as well as the amount of government debt that had already been substantial before the crisis and then further increased. The intriguing question for us was not to get information on how the burden was or is actually shared among the different layers of society in each of these countries but to find out how citizens felt that the burden should have been split up. In order to do this, we presented a hypothetical but hopefully not too unrealistic situation to students in economics and business administration courses and invited them to choose among different schemes of burden sharing or propose their own solution.

To be quite clear, the purpose of our study was not to compare countries that were hard hit with countries such as Germany which were affected to a minor degree only. Our question was twofold: (a) how would the proportional rule fare in all those countries that suffered significantly from the financial crisis which was unleashed in 2008, knowing that the proportional scheme did surprisingly well in investigations that had a different background; and (b) would the fact that some of these countries were more successful, whereas others were less successful in managing the crisis have an impact on the general attitude of how the burden should be or should have been shared?

In our instructions, we were relatively vague in relation to the question what the additional taxes should be used for, except that we spoke of "a large budget deficit". We did this on purpose. First of all, the students we contacted probably knew the economic and social situation within their own country so that they had at least a rough idea about what the levy of extra taxes would serve for. Secondly, and perhaps more important within a questionnaire study, any more concrete specification about where the additional taxes would go to might have led to particular reactions which, perhaps, should be avoided. If we had, for example, mentioned that the World Bank or the EU stood behind this measure, we would have elicited reactions which would have been different from the ones we would have engendered if we had said that the extra money went to the poor or again quite differently, if we had said that the additional tax revenues were needed to remedy grave mistakes from past governments.

Without restating our main results, two findings are of particular importance. First, the overwhelming majority of the undergraduates who participated in our study opted for a progressive and not for a proportional scheme of burden sharing. Did they just 
"confirm" or support the tax system in their own country to which they are accustomed as Miller (1992) has suggested? In our case, all countries involved are characterised by progressive income taxation systems. Hence Miller's scepticism or suspicion may be justified, given that students have exact or at least approximate knowledge about the degree of progressivity of their tax system, so that their answers will reflect or confirm the existing scheme. However, at least from our data we could not confirm this hypothesis. One could even come to a different inference. Our findings of a preference for a more progressive tax scheme in Greece are the expression of larger dissatisfaction with the present share of the burden expressed by the Gini coefficient and with the current degree of redistribution reflected by the Musgrave-Thin index in this country. Remember that questionnaire results do not predict or express actual behaviour but are a reflection of what would be desirable from the viewpoint of the person invited to respond (Gaertner and Schokkaert 2012, Chapter 2). Following this line, the opposite could be inferred with respect to Ireland. The Irish students' choice of the less progressive scheme may be an expression of their desire to have a smaller degree of redistribution than the current one. Let us repeat that all these inferences are made under the hypothesis that the undergraduates in our study are well informed about the actual tax schedule in their country and its effect on societal redistribution, an assumption which may not hold in every case.

However, admittedly, for the results that we reported, there may be other explanations as well but our data do not provide any additional clues. In future studies a more detailed questionnaire at the very end of the students' responses may, perhaps, provide a clearer picture. However, too many questions referring to personal characteristics and attitudes could well increase the number of cases where respondents might refuse to give an answer. One has to be very cautious on this matter.

As pointed out in the introduction, the proportional rule was the dominating scheme in several investigations that "come close" to our scenario, namely situations of bequest and bankruptcy where claims had been made that could not be satisfied. Our study has shown that the proportional rule clearly runs behind the two progressive schemes that we had offered for choice. Hence, at least on the macro level namely in the context of burden sharing called for by a severe financial crisis, progressive rather than proportional schemes are supported by the majority of students. In turn, this empirical observation can be used to refine tax schemes currently proposed in the literature.

The second finding of our study is, and this might have been expected, that Greece (Athens) and Ireland (Galway) are polar cases when it comes to a choice among the proportional rule and two variants of a progressive scheme. We should add that at least according to our study, students in Venice are close to those in Athens in relation to a preference for the second progressive scheme over the first, whereas they are closer to their counterparts from Galway in terms of support for the proportional solution. These observations may come as a surprise.

Acknowledgements We are extremely grateful to many colleagues without whose generous help this investigation would not have been possible. These were, in alphabetical order, Michele Bernasconi (Venice), Valeriya Dinger (Osnabrück), Byron Kaldis (Patras), Dunia López-Pintado and Juan Moreno-Ternero (Seville), Joana Pais (Lisbon), Ashley Piggins (Galway), Xavi Ramos (Barcelona), Antonio Romero-Medina (Madrid), Giovanni Sgritta (Rome), Yorgos Stassinopoulos (Athens), and Dimitrios Xefteris (Nicosia). Fur- 
thermore, we thank Marlies Ahlert, Thomas Kirschstein, György Széll and Katharina Friederike Sträter for very helpful comments and Tim Goldmann for his excellent research assistance. Various helpful suggestions of two anonymous referees of this journal are also gratefully acknowledged.

Open Access This article is distributed under the terms of the Creative Commons Attribution 4.0 International License (http://creativecommons.org/licenses/by/4.0/), which permits unrestricted use, distribution, and reproduction in any medium, provided you give appropriate credit to the original author(s) and the source, provide a link to the Creative Commons license, and indicate if changes were made.

\section{Appendix}

\section{Appendix A: "Rules" for questionnaire experiments on burden sharing}

Preliminary announcements (to be read out loud to the students before distributing the sheets)

- We kindly ask you to participate in this questionnaire experiment.

- It is part of a larger project dealing with the issue of burden sharing, run in various European countries.

- There may be a weak link to the topics of your current lecture or class, but not necessarily.

- The questionnaire contains one single decision problem, a field for comments you might like to add, and some socio-demographic questions.

- Note that there is no right or wrong answer for the decision problem.

- Instead, we are interested in your personal view on the problem described.

- Participation in this study is completely voluntary, but we would be happy to receive your personal contribution.

- All of your answers will be strictly kept anonymous.

- 10-15 min should be more than enough to answer our questionnaire.

- We kindly ask you now to stop any conversation.

- Please focus only on your own sheet.

- If there are any questions, do not ask your neighbours but complete the questionnaire as far as possible

Comment to the lecturer: the last three points intend to create an "exam atmosphere". The sheets can now be distributed. 


\section{Appendix B: The Questionnaire}

Consider the following study. Please remark that there is no right or wrong answer. We are exclusively interested in your opinion on the given problem.

Consider a country whose government is forced to levy additional taxes on its citizens for the coming years. The reason for this measure is that this country slipped into a financial crisis which led to a large budget deficit. In the country we consider, one can distinguish between five income groups of equal size. Before the financial crisis began, the average monthly income after tax per income group was as follows:

$(3600 ; 2400 ; 1500 ; 900 ; 600)$

The amount that the government has to raise each month comes up to $\underline{\mathbf{1 8 0 0}}$ units. How should this sum be split up among the different income groups?

In order to help you answer this question, various proposals are being offered which specify the income distribution after the introduction of the additional tax. Please indicate which of the proposals comes closest to your own view. In case you disagree with all proposals that are being made, you may specify your own tax scheme.

It is assumed that for each of the proposals made, the officially determined minimal income of the country always lies below the lowest income within each tax scheme.

\begin{tabular}{|c|c|c|c|c|c|c|c|c|c|}
\hline \multirow{3}{*}{ Group } & \multirow{3}{*}{$\begin{array}{c}\text { Net } \\
\text { income } \\
\text { before the } \\
\text { crisis }\end{array}$} & \multicolumn{8}{|c|}{ Net income after the introduction of the additional tax: } \\
\hline & & \multicolumn{8}{|c|}{ Proposals } \\
\hline & & (A) & (B) & (C) & (D) & (E) & $(\mathrm{F})$ & (G) & posal \\
\hline 1 & 3,600 & 3,240 & 2,880 & 2,700 & 2,500 & 2,100 & 2,736 & 2,520 & \\
\hline 2 & 2,400 & 2,040 & 1,920 & 1,900 & 1,900 & 2,100 & 1,824 & 1,680 & \\
\hline 3 & 1,500 & 1,140 & 1,200 & 1,250 & 1,350 & 1,500 & 1,140 & 1,500 & \\
\hline 4 & 900 & 540 & 720 & 800 & 860 & 900 & 900 & 900 & \\
\hline 5 & 600 & 240 & 480 & 550 & 590 & 600 & 600 & 600 & \\
\hline Sum & 9,000 & 7,200 & 7,200 & 7,200 & 7,200 & 7,200 & 7,200 & 7,200 & \\
\hline \multicolumn{2}{|c|}{$\begin{array}{l}\text { Your choice } \\
\text { (please tick) }\end{array}$} & $\mathrm{O}$ & $\mathrm{O}$ & $\mathrm{O}$ & $\mathrm{O}$ & $\mathrm{O}$ & $\mathrm{O}$ & $\mathrm{O}$ & \\
\hline
\end{tabular}

(Please also answer the back side) 


\section{Appendix B: The questionnaire (continued)}

Room for potential comments:

Finally we ask you for some personal information. Please keep in mind that the questionnaire is anonymous and your answers are only used for scientific purposes.
1. Gender:
O female
O male

2. Age: years

3. How would you rate your family's income ten years ago?

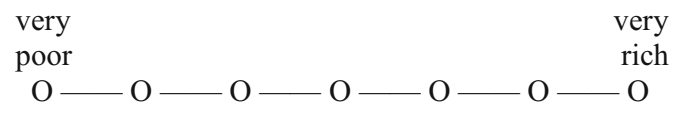

4. How would you rate your own income prospects in ten years?

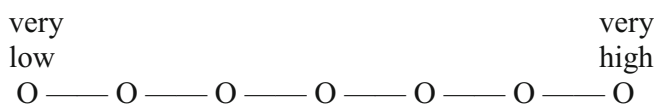

5. How would you rate your political view?

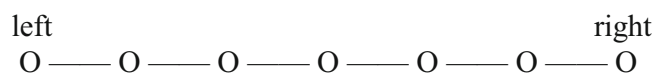

6. Did you change this political view within the last five years? O yes O no If "yes", please state "why".

\section{Thanks for your participation.}




\section{Appendix C: Pilot studies}

Table 9 Pilot study at Martin Luther University in Halle/Germany (May 2013)

\begin{tabular}{|c|c|c|c|c|c|c|c|c|c|}
\hline \multirow[t]{3}{*}{ Group } & \multirow{3}{*}{$\begin{array}{l}\text { Net income before } \\
\text { the crisis }\end{array}$} & \multicolumn{8}{|c|}{ Net income after the introduction of the additional tax } \\
\hline & & \multicolumn{8}{|c|}{ Proposals } \\
\hline & & (A) & (B) & (C) & (D) & (E) & $(\mathrm{F})$ & $(\mathrm{G})$ & Own proposal \\
\hline 1 & 3600 & 3240 & 2880 & 2100 & 3000 & 2700 & 2736 & 2520 & \\
\hline 2 & 2400 & 2040 & 1920 & 2100 & 1800 & 1500 & 1824 & 1680 & \\
\hline 3 & 1500 & 1140 & 1200 & 1500 & 900 & 1500 & 1140 & 1500 & \\
\hline 4 & 900 & 540 & 720 & 900 & 900 & 900 & 900 & 900 & \\
\hline 5 & 600 & 240 & 480 & 600 & 600 & 600 & 600 & 600 & \\
\hline Sum & 9000 & 7200 & 7200 & 7200 & 7200 & 7200 & 7200 & 7200 & \\
\hline \multicolumn{2}{|c|}{ Your choice (please tick) } & $\mathrm{O}$ & $\mathrm{O}$ & $\mathrm{O}$ & $\mathrm{O}$ & $\mathrm{O}$ & $\mathrm{O}$ & $\mathrm{O}$ & \\
\hline \multicolumn{2}{|c|}{ Answer frequencies $(\mathrm{N}=106)$} & $3.8 \%$ & $34.9 \%$ & $6.6 \%$ & $6.6 \%$ & $0.9 \%$ & $30.2 \%$ & $3.8 \%$ & $13.2 \%$ \\
\hline
\end{tabular}

Proposals are based on the following schemes: [place of the scheme in the final questionnaire]

(A) Constrained equal losses rule $[A]$.

(B) Proportional scheme $[B]$.

(C) Constrained equal awards rule $[E]$.

(D) Exempt the lowest two income groups, tax the upper three groups evenly [-].

(E) Exempt the lowest three income groups, tax the upper two groups evenly [-].

(F) Exempt the lowest two income groups, tax the upper three groups proportionally $[F]$.

(G) Exempt the lowest three income groups, tax the upper two groups proportionally $[G]$ (Table 9). 
Table 10 Pilot study at the University of Osnabrück/Germany (October 2013)

\begin{tabular}{|c|c|c|c|c|c|c|c|c|c|c|}
\hline \multirow[t]{3}{*}{ Group } & \multirow{3}{*}{$\begin{array}{l}\text { Net income before } \\
\text { the crisis }\end{array}$} & \multicolumn{9}{|c|}{ Net income after the introduction of the additional tax } \\
\hline & & \multicolumn{9}{|c|}{ Proposals } \\
\hline & & (A) & (B) & (C) & (D) & (E) & (F) & (G) & $(\mathrm{H})$ & Own proposal \\
\hline 1 & 3600 & 3240 & 2880 & 2700 & 2100 & 3000 & 2700 & 2736 & 2520 & \\
\hline 2 & 2400 & 2040 & 1920 & 1900 & 2100 & 1800 & 1500 & 1824 & 1680 & \\
\hline 3 & 1500 & 1140 & 1200 & 1250 & 1500 & 900 & 1500 & 1140 & 1500 & \\
\hline 4 & 900 & 540 & 720 & 800 & 900 & 900 & 900 & 900 & 900 & \\
\hline 5 & 600 & 240 & 480 & 550 & 600 & 600 & 600 & 600 & 600 & \\
\hline Sum & 9000 & 7200 & 7200 & 7200 & 7200 & 7200 & 7200 & 7200 & 7200 & \\
\hline \multicolumn{2}{|c|}{ Your choice (please tick) } & $\mathrm{O}$ & $\mathrm{O}$ & $\mathrm{O}$ & $\mathrm{O}$ & $\mathrm{O}$ & $\mathrm{O}$ & $\mathrm{O}$ & $\mathrm{O}$ & $\mathrm{O}$ \\
\hline \multicolumn{2}{|c|}{ Answer frequencies $(\mathrm{N}=85)$} & $1.2 \%$ & $14.1 \%$ & $54.1 \%$ & $5.9 \%$ & $4.7 \%$ & $1.2 \%$ & $12.9 \%$ & $1.2 \%$ & $4.7 \%$ \\
\hline
\end{tabular}

Proposals are based on the following schemes: [place of the scheme in the final questionnaire]

(A) Constrained equal losses rule $[A]$.

(B) Proportional scheme $[B]$.

(C) Progressive scheme $[C]$.

(D) Constrained equal awards rule $[E]$.

(E) Exempt the lowest two income groups, tax the upper three groups evenly [-].

(F) Exempt the lowest three income groups, tax the upper two groups evenly [-].

(G) Exempt the lowest two income groups, tax the upper three groups proportionally $[F]$.

(H) Exempt the lowest three income groups, tax the upper two groups proportionally $[G]$ (Table 10). 
Table 11 Pilot study at the Universidad Pablo de Olavide, Seville/Spain (January 2014)

\begin{tabular}{|c|c|c|c|c|c|c|c|c|c|c|}
\hline \multirow[t]{3}{*}{ Group } & \multirow{3}{*}{$\begin{array}{l}\text { Net income before } \\
\text { the crisis }\end{array}$} & \multicolumn{9}{|c|}{ Net income after the introduction of the additional tax } \\
\hline & & \multicolumn{9}{|c|}{ Proposals } \\
\hline & & (A) & (B) & (C) & (D) & (E) & (F) & $(\mathrm{G})$ & $(\mathrm{H})$ & Own proposal \\
\hline 1 & 3600 & 3240 & 2880 & 2700 & 2100 & 3000 & 2700 & 2736 & 2520 & \\
\hline 2 & 2400 & 2040 & 1920 & 1900 & 2100 & 1800 & 1500 & 1824 & 1680 & \\
\hline 3 & 1500 & 1140 & 1200 & 1250 & 1500 & 900 & 1500 & 1140 & 1500 & \\
\hline 4 & 900 & 540 & 720 & 800 & 900 & 900 & 900 & 900 & 900 & \\
\hline 5 & 600 & 240 & 480 & 550 & 600 & 600 & 600 & 600 & 600 & \\
\hline Sum & 9000 & 7200 & 7200 & 7200 & 7200 & 7200 & 7200 & 7200 & 7200 & \\
\hline \multicolumn{2}{|c|}{ Your choice (please tick) } & $\mathrm{O}$ & $\mathrm{O}$ & $\mathrm{O}$ & $\mathrm{O}$ & $\mathrm{O}$ & $\mathrm{O}$ & $\mathrm{O}$ & $\mathrm{O}$ & $\mathrm{O}$ \\
\hline \multicolumn{2}{|c|}{ Answer frequencies $(\mathrm{N}=67)$} & $3.0 \%$ & $6.0 \%$ & $43.3 \%$ & $6.0 \%$ & $10.4 \%$ & $9.0 \%$ & $16.4 \%$ & $6.0 \%$ & $0.0 \%$ \\
\hline
\end{tabular}

Proposals are based on the following schemes: [place of the scheme in the final questionnaire]

(A) Constrained equal losses rule $[A]$.

(B) Proportional scheme $[B]$.

(C) Progressive scheme $[C]$.

(D) Constrained equal awards rule $[E]$.

(E) Exempt the lowest two income groups, tax the upper three groups evenly [-].

(F) Exempt the lowest three income groups, tax the upper two groups evenly [-].

(G) Exempt the lowest two income groups, tax the upper three groups proportionally $[F]$.

(H) Exempt the lowest three income groups, tax the upper two groups proportionally $[G]$ (Table 11). 
Table 12 Pilot study at Sapienza University of Rome/Italy (October 2013)

\begin{tabular}{|c|c|c|c|c|c|c|c|c|c|c|}
\hline \multirow[t]{3}{*}{ Group } & \multirow{3}{*}{$\begin{array}{l}\text { Net income before } \\
\text { the crisis }\end{array}$} & \multicolumn{9}{|c|}{ Net income after the introduction of the additional tax } \\
\hline & & \multicolumn{9}{|c|}{ Proposals } \\
\hline & & (A) & (B) & (C) & (D) & (E) & (F) & (G) & $(\mathrm{H})$ & Own proposal \\
\hline 1 & 3600 & 3240 & 2880 & 2700 & 2100 & 3000 & 2700 & 2736 & 2520 & \\
\hline 2 & 2400 & 2040 & 1920 & 1900 & 2100 & 1800 & 1500 & 1824 & 1680 & \\
\hline 3 & 1500 & 1140 & 1200 & 1200 & 1500 & 900 & 1500 & 1140 & 1500 & \\
\hline 4 & 900 & 540 & 720 & 720 & 900 & 900 & 900 & 900 & 900 & \\
\hline 5 & 600 & 240 & 480 & 480 & 600 & 600 & 600 & 600 & 600 & \\
\hline Sum & 9000 & 7200 & 7200 & 7200 & 7200 & 7200 & 7200 & 7200 & 7200 & \\
\hline \multicolumn{2}{|c|}{ Your choice (please tick) } & $\mathrm{O}$ & $\mathrm{O}$ & $\mathrm{O}$ & $\mathrm{O}$ & $\mathrm{O}$ & $\mathrm{O}$ & $\mathrm{O}$ & $\mathrm{O}$ & $\mathrm{O}$ \\
\hline \multicolumn{2}{|c|}{ Answer frequencies $(\mathrm{N}=33)$} & $0.0 \%$ & $12.1 \%$ & $42.4 \%$ & $3.0 \%$ & $3.0 \%$ & $0.0 \%$ & $21.2 \%$ & $6.1 \%$ & $12.1 \%$ \\
\hline
\end{tabular}

Proposals are based on the following schemes: [place of the scheme in the final questionnaire]

(A) Constrained equal losses rule $[A]$.

(B) Proportional scheme $[B]$.

(C) Progressive scheme $[C]$.

(D) Constrained equal awards rule $[E]$.

(E) Exempt the lowest two income groups, tax the upper three groups evenly [-].

(F) Exempt the lowest three income groups, tax the upper two groups evenly [-].

(G) Exempt the lowest two income groups, tax the upper three groups proportionally $[F]$.

(H) Exempt the lowest three income groups, tax the upper two groups proportionally $[G]$ (Table 12).

\section{References}

Amiel Y, Cowell FA (1999) Thinking about inequality. Cambridge University Press, Cambridge

Aumann RJ, Maschler M (1985) Game theoretic analysis of a bankruptcy problem from the Talmud. J Econ Theory 36:195-213. doi:10.1016/0022-0531(85)90102-4

Bosmans K, Schokkaert E (2009) Equality preferences in the claims problem: a questionnaire study of cuts in earnings and pensions. Soc Choice Welf 33:533-557. doi:10.1007/s00355-009-0378-4

Carlsson F, Daruvala D, Johansson-Stenman O (2005) Are people inequality-averse, or just risk-averse? Economica 72:375-396. doi:10.1111/j.0013-0427.2005.00421.x

Chambers CP, Moreno-Ternero JD (2016) Taxation and poverty. Soc Choice Welf (forthcoming). doi:10. 1007/s00355-015-0905-4

Engelmann D, Strobel M (2004) Inequality aversion, efficiency, and maximin preferences in simple distribution experiments. Am Econ Rev 94:857-869. doi:10.1257/0002828042002741

Eurostat (2016a) Unemployment rates by sex, age and nationality. http://ec.europa.eu/eurostat/tgm/table. do? tab=table \&init=1\&language=en \&pcode=tipsun30\&plugin=1. Accessed 19 Oct 2016

Eurostat (2016b) Gini coefficient of equivalised disposable income. http://ec.europa.eu/eurostat/tgm/table. do?tab=table \&init=1\&language=en\&pcode=tessi190\&plugin=1. Accessed 19 Oct 2016

Gächter S, Riedl A (2006) Dividing justly in bargaining problems with claims: normative judgments and actual negotiations. Soc Choice Welf 27:571-594. doi:10.1007/s00355-006-0141-z 
Gaertner W, Schokkaert E (2012) Empirical social choice: questionnaire-experimental studies on distributive justice. Cambridge University Press, Cambridge

Herrero C, Villar A (2001) The three musketeers: four classical solutions to bankruptcy problems. Math Soc Sci 42:307-328. doi:10.1016/S0165-4896(01)00075-0

Herrero C, Moreno-Ternero JD, Ponti G (2010) On the adjudication of conflicting claims: an experimental study. Soc Choice Welf 34:145-179. doi:10.1007/s00355-009-0398-0

Ju B-G, Moreno-Ternero JD (2008) On the equivalence between progressive taxation and inequality reduction. Soc Choice Welf 30:561-569. doi:10.1007/s00355-007-0254-z

Miller D (1992) Distributive justice: what the people think. Ethics 102:555-593. doi:10.1086/293425

Moreno-Ternero JD, Villar A (2004) The Talmud rule and the securement of agents' awards. Math Soc Sci 47:245-257. doi:10.1016/S0165-4896(03)00087-8

Moulin H (2002) Axiomatic cost and surplus-sharing. In: Arrow KJ, Sen A, Suzumura K (eds) The handbook of social choice and welfare, vol 1. Elsevier, Amsterdam, pp 289-357

Musgrave RA, Thin T (1948) Income tax progression 1929-48. J Polit Econ 56:498-514. doi:10.1086/ 256742

OECD Income Distribution Database [OECD] (2014) Terms of reference: OECD project on the distribution of household incomes. 2014/15 collection, October 2014. http://www.oecd.org/els/soc/IDD-ToR.pdf. Accessed 19 Oct 2016

OECD.Stat (2016) Income distribution and poverty. http://stats.oecd.org/Index.aspx?DataSetCode=IDD. Accessed 19 Oct 2016

Schokkaert E, Overleat B (1989) Moral intuitions and economic models of distributive justice. Soc Choice Welf 6:19-31. doi:10.1007/BF00433360

Sheskin DJ (2011) Handbook of parametric and nonparametric statistical procedures, 5th edn. Chapman \& Hall, Boca Raton

Thomson W (2003) Axiomatic and game-theoretic analysis of bankruptcy and taxation problems: a survey. Math Soc Sci 45:249-297. doi:10.1016/S0165-4896(02)00070-7

Thomson W (2011) Fair allocation rules. In: Arrow KJ, Sen A, Suzumura K (eds) The handbook of social choice and welfare, vol 2. Elsevier, Amsterdam, pp 393-506

Thomson W (2013) A characterization of a family of rules for the adjudication of conflicting claims. Game Econ Behav 82:157-168. doi:10.1016/j.geb.2013.07.002

Thomson W (2015) Axiomatic and game-theoretic analysis of bankruptcy and taxation problems: An update. Math Soc Sci 74:41-59. doi:10.1016/j.mathsocsci.2014.09.002

Young P (1988) Distributive justice in taxation. J Econ Theory 44:321-335. doi:10.1016/ 0022-0531(88)90007-5 